\title{
Expediciones, narrativas y utopías: nuevas miradas sobre el "espacio guaraní-misionero" hacia fines del siglo XVIII
}

\author{
Expeditions, narratives and utopias: new perspectives above the \\ territory "guaraní-misionero" toward the end of the $18^{\text {th }}$ century
}

\author{
Lía Quarleri*
}

\section{RESUMEN}

El siglo XVIII inauguró en América el "viaje científico" del que participaron botánicos, naturalistas, cartógrafos, ingenieros y marinos, que dio inicio a una intervención diferente sobre los territorios coloniales combinando nuevos conocimientos con una política de corte absolutista. En el Río de la Plata, esto tomó un giro notable tras la expulsión de los jesuitas, con la instauración de un nuevo régimen misionero entre los guaraníes antes administrados por ellos y en virtud del despliegue de un aparato de reconocimiento y exploración que se incrementó con el Tratado de San Ildefonso firmado entre España y Portugal en 1777. Diversas perspectivas, bajo objetivos asociados al engrandecimiento del estado borbónico y a la delimitación y reconocimiento territorial, guiaron las relaciones, crónicas y memorias efectuadas durante las últimas décadas del siglo XVIII en el espacio ocupado por las antiguas misiones guaraníes. En el presente trabajo interesa dar cuenta de qué forma sujetos tales como Félix de Azara, Diego de Alvear y Gonzalo de Doblas dieron un lugar notable al poder a la escritura y a la observación con el fin de registrar información de diversa índole, sugerencias y "noticias útiles al servicio del Rey" dentro de un marco ideológico determinado y en relación con un espacio, las misiones guaraníes, portadoras de una historia particular que alimentó un imaginario prolifero y amplio a ambos lados del Atlántico.

PALABRAS ClavES: Expedicionarios - Río de la Plata. Misiones guaraníes. Historia natural.

\section{ABSTRACT}

In America the 18th century gave way to the "scientific journey" involving botanists, naturalists, cartographers, engineers and sailors, which meant a different intervention on colonial Territories by combining new knowledge with an absolutist policy. In the Río de la Plata, this took a notable turn after the expulsion of the Jesuits, with the establishment of a new regime among the Guarani previously administered by them and in relation to the deployment of a device of recognition and exploration which rose with the Treaty of San Ildefonso, signed between Spain and Portugal in 1777. Diverse perspectives, determined by goals associated with the aggrandizement of the borbonicus State and delimitation and territorial recognition, guided the relations, the Chronicles and reports made during the last decades of the 18th century in America. This paper will analyse how administrators such as Félix de Azara, Diego de Alvear y Gonzalo Doblas gave a remarkable power to the writing and the observation to record information of diverse nature, suggestions and "Useful news to the service of the King" all guided by an ideological framework in particular. These reports focused on the Guarani missions, which had a particular story that had fed an imaginary on both sides of the Atlantic for his legendary wealth.

KEYWORDS: Expedition - Río de la Plata. Guaraní missions. Natural history.

\footnotetext{
* Doctora en Antropología social de la Universidad de Buenos Aires. Investigadora Adjunta del Consejo Nacional de Investigaciones Científicas y Técnicas (CONICET) y del Instituto de Altos Estudios Sociales (IDAES). Correo electrónico: liaquarleri@yahoo.com.ar
} 
El siglo XVIII inauguró en América el "viaje científico" del que participaron botánicos, naturalistas, cartógrafos, ingenieros y marinos, que dio inicio a una intervención diferente sobre los territorios coloniales combinando nuevos conocimientos con una política de corte absolutista. Así, la delimitación de territorios por consenso político y gracias a las nuevas técnicas militares y científicas desarrolladas proyectaba dejar atrás la posesión de extensas regiones por medio de conquistas y enfrentamientos bélicos. Los nuevos emprendimientos, a su vez, respondían a la necesidad de incrementar el conocimiento sobre el espacio, sus límites, potencialidades y características, como el de la población que habitaba el mismo, para alcanzar un mayor control social y político. En particular, las áreas de frontera entre los Imperios español y portugués o las zonas internas aún no dominadas fueron áreas privilegiadas para el emprendimiento de renovadas "etnografías estatales" bajo impetuosos comisionados o expertos en diferentes disciplinas'1.

En el Río de la Plata, esto tomó un giro notable tras la expulsión de los jesuitas, con la instauración de un nuevo régimen misionero entre los guaraníes antes administrados por ellos y en virtud del despliegue de un aparato de reconocimiento y exploración que se incrementó con el Tratado de San Ildefonso firmado entre España y Portugal en 1777. La "Expedición a la América Meridional” (1779-1801) enviada por los Borbones para delimitar las nuevas fronteras con Portugal fue en sí misma un proyecto que combinó una dimensión pragmática con otra utópica. Esto en virtud, por un lado, de la confianza absoluta en el proyecto experimental sobre sociedades y paisajes que se presentaban como modélicos (ALBERT, 1996, p. 252-253) como de la distancia con la realidad local manifestada en las Relaciones elaboradas por los demarcadores y administradores misioneros. Diversas perspectivas, bajo objetivos asociados al engrandecimiento del estado borbónico y a la delimitación y reconocimiento territorial, guiaron las relaciones, crónicas y memorias efectuadas durante las últimas décadas del siglo XVIII en el espacio ocupado por las antiguas misiones guaraníes. En el presente trabajo interesa dar cuenta de qué forma sujetos tales como Félix de Azara, Diego de Alvear y Gonzalo de Doblas dieron un lugar notable al poder a la escritura y a la observación con el fin de registrar información de diversa índole, sugerencias y "noticias útiles al servicio del Rey"2 dentro de un marco ideológico determinado y en

\footnotetext{
1 El término "etnografías estatales" utilizado también por otros autores (Wilde, 2003) alude aquí al trabajo de reconocimiento in situ, relevamiento de información y observaciones realizadas por diferentes funcionarios con fines políticos y científicos.

2 Carta de Gonzalo de Doblas al Señor Don Félix de Azara Capitán de fragata de la Real Armada y comandante de la tercera partida de la demarcación de límites con Portugal, por la provincia del Paraguay. IN Pedro de Angelis (comp.). Colección de obras y documentos relativos a la historia
} 
relación con un espacio, las misiones guaraníes, portadoras de una historia particular que alimentó un imaginario prolifero y amplio a ambos lados del Atlántico.

Al respecto cabe aclarar que los comisionados y administradores Félix de Azara, Diego de Alvear y Gonzalo de Doblas, entre otros, escribieron sus Relaciones o Memorias sobre la "provincia de misiones de indios guaraníes" o sobre el "territorio de las misiones" en el contexto de un cambio de paradigma político sobre estos pueblos y su territorio que influyo en las miradas y perspectivas depositadas en las narrativas elaboradas. En este sentido, aunque hacia fines de siglo XVIII la frontera con Portugal continuaba siendo un tema de extrema delicadeza, las percepciones volcadas en las Relaciones oficiales sobre los pueblos guaraníes y el espacio fronterizo no estarán determinadas tanto por su valuarte defensivo como por los objetivos expedicionarios de demarcación bajo los nuevos instrumentos de medición y por las nuevas utopías ligadas a los conceptos de industria, comercio y productividad. Al respecto, si bien la tendencia ha sido quitarle dimensión utópica a la Ilustración española en virtud de su vertiente pragmática, económica y utilitaria la fuerte presencia de un ideal de cambio basado en una confianza en el progreso, la educación y la industria y en las potenciales de los recursos y espacios abordados más allá de las condiciones locales, reflejado en sus principales exponentes matiza dicha postura ${ }^{3}$. Esta proyección trasformadora se enfrentó sin embargo con las lógicas y tiempos locales e imperiales que fueron consumiendo el "sueño político" de los demarcadores (LUCENA GIRALDO, 1996, p. 272). Las complicaciones y demoras surgidas en los procesos demarcatorios dieron lugar a que, en 1801, los portugueses ocuparan la banda oriental del Uruguay contraviniendo los pactos previos.

Existe una amplia bibliografía que ha abordado las reformas borbónicas, en general, y en menor medida que se ha focalizado en la temática espacial y fronteriza. Con respecto a estos trabajos interesa mencionar aquellos que han estudiados espacios de frontera y a las comunidades o poblaciones indígenas asociadas a los mismos en las áreas vinculadas con los Imperios de España y Portugal como parte de las reformas borbónicas y pombalinas (ARECES, 2007; GARCIA FRÜHAUF, 2007; HEINSFELD, 2006; LANGER, 2005; LAZARO AVILA, 1996, 1997; LUCENA GUIRALDO, 1996; MAEDER, 1986; WILDE, 2003). Este período de mayor impronta reformista fue acompañado de expediciones científico-militares que buscaban cumplir con las tareas

antigua y moderna de las provincias del Río de la Plata. Buenos Aires, Editorial Plus Ultra, 1970, p. 21-22.

3 Véase al respecto las diferentes definiciones de utopía señaladas por Salvador Bernabeu Albert así como su reflexión en torno a la ilustración española, el reformismo borbónico y las utopías de cambio social (ALBERT, 1996, p. 251). 
de demarcación fronteriza como con la tarea oficial de recabar información de índole geográfica, económica, botánica y poblacional. Con respecto a esto último es de fundamental importancia señalar aquellos trabajos que han focalizado en la experiencia de viaje y en sus narrativas como parte de una dimensión particular de construcción de las relaciones políticas imperiales (ALTUNA, 2002; CICERCHIA, 2000, 2005; ESCOLAR, 1996; LUCENA GIRALDO, 2003; MORO-ROMERO, 2003; PENHOS, 2005; PERRONE, 1973; PRATT, 1997; RIPODAZ ARDAÑAZ, 2002; SAN PÍO, 1992; WILDE, 2007). En relación al espacio guaraní-misionero no son pocos los trabajos que han estudiado el régimen misionero después de las expulsión de los jesuitas abarcando las dimensiones económicas, patrimoniales, demográficas, administrativas y en menor medida geopolíticas (HERNANDEZ, 1999, 2002; MAEDER, 1992; POETNIZ; POETNIZ, 1998; SANTOS; BAPTISTA, 2007; SARREAL, 2008; WILDE; 2001, 2009, para citar solo algunos autores) ${ }^{4}$.

$\mathrm{Si}$ bien contamos con bibliografía que ha abordado las narrativas oficiales sobre las fronteras del Río de la Plata a fines del siglo XVIII esta no han dado cuenta de las contradicciones entre el ideal narrativo y la diversidad y complejidad de las situaciones o perspectivas locales existentes en el período que se abre tras la expulsión de los jesuitas. El objetivo es comprender de qué forma expedicionarios, funcionarios o administradores como Azara, Alvear y Doblas interpelaron al "espacio" misionero, en qué repararon, y que diferencias pueden observarse entre ellos, asumiendo nuevos criterios de verdad ligados a la experiencia y al uso de la razón en alianza con la geografía, la política y la economía.

\section{El Espacio Guaraní-Misionero Hacia Fines del Siglo XVIII}

Tras la expulsión de los jesuitas de todos los dominios españoles, en la misiones guaraníes se estableció un régimen de administración secular adaptado a las

\footnotetext{
4 Entendemos en este caso al espacio guaraní-misionero como una unidad de sentido en virtud de una trayectoria histórica determinada por lógicas jurisdiccionales y políticas que subsistieron hasta fines del XVIII. Tras la expulsión de los jesuitas, las treinta reducciones se mantuvieron bajo un mismo régimen divididos en dos distritos, el de Paraná y el de Uruguay, dentro de la jurisdicción de Buenos Aires. La designación de dos gobernadores duró solo un año, ya que a partir de 1769 se mantuvo uno solo de ellos y se nombraron tres tenientes de gobernador. En 1774 se crearon nuevas agrupaciones llegando a estar los pueblos supeditados a los departamentos de Santiago, San Miguel, Yapeyú., Concepción y Candelaria. Con la Real Ordenanza de Intendentes Concepción y Candelaria pasaron a depender del Paraguay y los otros tres departamentos a Buenos Aires. El giro y cambio estructural se produjo en 1801 con la ocupación del departamento de San Miguel, al este del río Uruguay por Portugal, y luego con el impacto general que produjeron sobre este territorio las guerras independentistas.
} 
estructura que habían montado los ignacianos ${ }^{5}$. En este sentido, se mantuvo el sistema de pueblos, con sus cabildos y corregidores, que tanta fuerza había tenido bajo el período jesuita y los atributos de distinción y autoridades de la elite indígena para sobre cada uno de ellos montar un mecanismo de gobierno, supervisión y control directo a partir de la designación de administradores laicos. Los funcionarios nombrados fueron los encargados de supervisar el trabajo de los curas, limitando su participación en asuntos económicos y políticos. Paralelamente, se concibió una tibia política de defensa de la frontera para lo que designó a los capitanes Bruno de Zavala y Juan Francisco de la Riva Herrera como gobernadores interinos de las misiones. Al primero, encargado de los diez pueblos del Uruguay, se le asignó la defensa de la frontera portuguesa. Al poco tiempo, se desplazó a Herrera y se nombró a tenientes que debían asumir también la defensa del territorio contra los ataques de los indios del Chaco y de los charrúas. El territorio de las misiones se constituyó a partir de las nuevas instrucciones en una jurisdicción subordinada a la gobernación de Buenos Aires (MAEDER, 1992; POETNIZ; POETNIZ, 1998).

De la misma forma que en otras jurisdicciones coloniales, donde los bienes de los jesuitas pasaron a ser administrados por un conjunto de autoridades locales, las disputas, fraudes y abusos se constituyeron en materia corriente, con el agregado que los intereses y presiones que recayeron sobre el espacio misionero por su disposición de "milicianos", mano de obra, y tierras productivas complejizaron el panorama ${ }^{6}$. Los pueblos guaraníes, aunque sin la previsión y contrapartidas dispuestas en los tiempos jesuíticos, siguieron constituyéndose en jurisdicción de frontera y centro de provisión de bienes comerciales y trabajadores. La naturalización de los abusos y la explotación laboral, sobre un conjunto numeroso de personas expuestas a una capa de autoridades y gobernadores que actuaban bajo políticas de carácter cada vez menos proteccionistas, manifestó una ruptura en las relaciones previamente adoptadas por la Corona de España sobre las comunidades indígenas. Ante las abusivas cargas laborales impuestas, sumadas a las epidemias de viruela, se produjo un ciclo de fugas como de motines a lo largo de las últimas décadas del siglo XVIII (HERNANDEZ, 1999; SARREAL, 2008).

\footnotetext{
${ }^{5}$ Existe acuerdo en concebir al regalismo de la segunda mitad del siglo XVIII, que promulgaba la supremacía del Rey sobre las materias eclesiásticas, como la base ideológica del decreto de extrañamiento que se configuró tanto dentro de una atmósfera europea de cambios políticos e intelectuales como de reformas en la relación entre el poder eclesiástico y los estados monárquicos.

${ }^{6}$ De forma inmediata a la extradición de los religiosos, el estado confiscó sus bienes y se crearon "Administraciones de Temporalidades" en todas las jurisdicciones en las que los jesuitas habían creado o solventado colegios, estancias, haciendas y reducciones. La gestión de Temporalidades dio lugar a pugnas por el control de los cargos, los bienes, así como de fraude, malversación y favoritismo y los establecimientos padecieron un proceso de devaluación frente al deterioro edilicio, la venta de la mano de obra y la baja de los niveles productivos (QUARLERI, 2001).
} 
No obstante pese a los ciclos de epidemias y fugas y al estado de deterioro de los establecimientos edilicios las autoridades, administradores y comerciantes continuaron sacando el máximo provecho posible de los bienes disponibles. Ante el auge de una política de neto corte comercial que impregnó a la sociedad colonial y a la administración borbónica se levantaron voces diversas que cuestionaron el rendimiento y la eficiencia productiva de los establecimientos misioneros bajo la continuidad de un régimen comunal de productividad (HERNANDEZ, 2002). Mientras tanto y pese al notable descenso demográfico de la población guaraní se fundaron, con familias de ese origen, nuevos asentamientos en el noroeste de Entre Ríos, entre 1777 y 1782, y desde la frontera sur localizada en los establecimientos de Yapeyú se expandió la frontera ganadera (MAEDER, 1992). Asimismo, las estancias de los pueblos mantuvieron una participación muy elevada en la comercialización de cueros vacunos y carnes saladas que se vio favorecida por el reglamento de Libre comercio que desde 1778 abrió el intercambio entre los puertos de Buenos Aires y Montevideo con España, antes limitado o restringido de acuerdo al caso.

Dentro de este contexto, la utopía ligada al engrandecimiento del estado borbónico, en base a políticas comerciales de corte liberal y a medidas que garantizasen la "utilidad pública" de los territorios coloniales, alimentó una narrativa inspirada en las potenciales misioneras y en los frutos resultantes de ellas. Esto sumado al auge de las expediciones de exploración y reconocimiento de territorios fronterizos inspiró la convergencia del interés científico de la época con el afán por el dominio político y económico que caracterizó al gobierno de los últimos borbones. Todo ello quedó expresado en las relaciones escritas en la coyuntura de la Expedición de Límites enviada por las Coronas ibéricas para cumplir con las consignas del Tratado de San Ildefonso.

\section{Las Expediciones de Límites: Política, Ciencia y Utopía}

Las misiones jesuitas de guaraníes, desde su origen, estuvieron vinculadas a la defensa del territorio de la Corona española contra los portugueses, cuyas acciones expansivas ponían en jaque los dominios españoles esbozados tempranamente por el Tratado de Tordesillas. No obstante, el avance lusitano se hizo efectivo con la fundación de Colonia de Sacramento, en 1680, y de nuevos enclaves en la costa Atlántica desde fines del siglo XVII. Con la firma del Tratado de Madrid, en 1750, se inició un nuevo período marcado por la política diplomática y las expediciones de reconocimiento y 
demarcación de Límites7. Hacia la década de 1770, dentro del contexto de reformas borbónicas asociadas al afianzamiento de políticas mercantiles y territoriales, la Corona de España intentó por diferentes vías sin éxito recuperar territorios en manos lusitanas. Finalmente se proyectó una política más agresiva de defensa y ocupación de territorios (GOLIN, 2002) ${ }^{8}$. Para ello se envío al Río de la Plata una expedición de guerra al mando de Don Pedro de Ceballos y luego de un breve período de enfrentamientos armados entre ambas potencias, en territorios coloniales, se negoció la Paz y se firmó, el 1 de octubre de 1777, el Tratado Preliminar de límites de América Meridional, conocido como Primer Tratado de San Ildefonso ${ }^{9}$.

Dentro de un clima de acuerdo entre ambas Coronas se buscó poner fin a los conflictos bélicos y cumplir con los pactos de límites establecidos. El Tratado de San Ildefonso firmado entre España y Portugal a diferencia de su precedente, el Tratado de Madrid (1750), daba más margen de acción a España. Es así que a través del Tratado Límites de 1777 España conservaba los siete pueblos de misiones y recobraba Colonia del Sacramento y le devolvía a Portugal la isla de Santa Catalina y otros territorios en la colonia de Río Grande de San Pedro, ocupados recientemente por las fuerzas de Pedro de Ceballos. Para hacer efectivo el Tratado, las Coronas ibéricas ordenaron tareas de demarcación por medio de la designación de comisiones bilaterales que estarían encargadas, además, del estudio geográfico, sustentado en la prestigiosa formación cartográfica de sus miembros (MAZZOLA, 2008). La Expedición a la América Meridional, al mando de J osé Varela y Ulloa, partió de Lisboa en enero de 1781. Una vez en el Río de la Plata, por orden del Virrey, la Expedición fue dividida en cuatro partidas bajo el mando de J osé Varela y Ulloa, Diego de Alvear, Félix de Azara y J uan Francisco de Aguirre. Las partidas quedaron compuestas, cada una de ellas, por "dos

\footnotetext{
7 Por el tratado de Límites de 1750 se entregaba a Portugal parte del territorio oriental de las misiones a Portugal a cambio de Colonia de Sacramento. Sin embargo, tras una resistencia activa de los caciques guaraníes y un cambio en la política ibérica, el Tratado se anuló y España y Portugal entraron nuevamente en guerra hasta la firma de la Paz de París, en 1763. Este tema fue trabajado de forma específica en (QUARLERI, 2009).

8 Dentro de este plan se proyectaba recuperar Río Grande de San Pedro y la Isla Santa Catalina en manos portuguesas "por cuyas aguas pasaría el meridiano de la demarcación, según las observaciones astronómicas que subsisten" y se convenía que "si los plenipotenciarios lusitanos se negaban absolutamente a ello [...] no nos quedaría a nosotros otro recurso decente que el de la guerra". Puntos que se han de tratar y decidir por los señores Secretarios de Estado y del Despacho para formar la instrucción que se ha de dar al Conde Aranda sobre los términos en que debe comportarse en la negociación de Límites de América Meridional. Madrid, 30 de mayo de 1776. Archivo Histórico Nacional de Madrid (AHNM), Sección Estado, Legajo 4798, documento 381, fojas 2 y 3.

9 Este Tratado fue firmado por el conde de Floridablanca y Francisco Inocencio de Souza Coutinho, y ratificado por la Paz del Pardo en 1778. La constitución de una coyuntura diplomática fue favorecida por la sucesión al trono de María I, sobrina de Carlos III de España, tras la muerte del Rey J osé I de Portugal, como por la caída del Marqués de Pombal.
} 
comisarios, uno o dos ingenieros, dos geógrafos y dos prácticos, con la gente proporcionada al servicio de sus encargos" con el fin determinar

\begin{abstract}
los sitios en que deberían unirse unos y otros dependientes, para empezar sus respectivas operaciones: el rumbo y paraje por donde deben caminarse, y sitios donde rejuntasen, para resolver de común acuerdo la demarcación que se habrá de seguir y lo demás que pudiera ocurrir a la vista del terreno en conformidad de los respectivos artefactos del respectivo Tratado Preliminar ${ }^{10}$.
\end{abstract}

Para cumplir con sus propósitos su sumó a cada una de ellas un contingente de "dragones", con sus respectivos tenientes, y se aprovisionaron las tropas con víveres para ocho meses de trayecto. La idea era concluir con "brevedad, y sin mucha incomodidad, respecto a que se ha de ejecutar por un terreno trillado y conocido, con pocos o ningunos ríos que pasar"11. En este sentido, se contaba con la experiencia dejada por la expedición al Río de la Plata, realizada veinte años atrás, luego de la firma del Tratado de Madrid. Esta había penetrado en territorios desconocidos o recónditos de forma oficial por los españoles o portugueses y recabado información diversa, marcando un hito histórico y una novedosa forma de ingerencia que combinó un proyecto colonizador con un plan de reconocimiento geográfico y cartográfico. Sin embargo la nueva expedición guardaba otros objetivos asociados al auge mercantil y a la vertiente ibérica del iluminismo y el conocimiento enciclopédico. Ya no interesaba localizar minas o riquezas ocultas, como si ocurrió en la expedición luso-española de la década de 1750, sino "descubrir" y describir las potencialidades de los territorios americanos, delimitar sus jurisdicciones, reorientar la población indígena o campesinas hacia canales productivos con rentas para el estado, comercializar los productos de la tierra en relación con la demanda y controlar o erradicar las rebeliones o procesos de resistencia locales. De esta forma, pese a la tarea especificada de demarcación, las partidas se transformaron en empresas de expedición y reconocimiento con fines políticos, económicos, científicos y militares.

La Expedición estipulada tras la firma del Tratado de San Ildefonso contó con instrucciones generales que determinaban la forma de llevar a cabo el proceso de delimitación y amojonamiento como el tipo de información y datos a recabar. En ellas

10 Diario de la Segunda Partida de la Demarcación de Límites entre los Dominios de España y Portugal en la América Meridional por el comisario de ella el Teniente de Navío de la Real Armada Don Diego de Alvear y Escalera. Archivo General de la Nación (AGN), Sala VII, Colección Biblioteca Nacional, documento 36, foja 2.

11 Diario de la Segunda Partida de la Demarcación de Límites entre los Dominios de España y Portugal en la América Meridional por el comisario de ella el Teniente de Navío de la Real Armada Don Diego de Alvear y Escalera. Archivo General de la Nación (AGN), Sala VII, Colección Biblioteca Nacional, documento 36, foja 9. 
se estipularon la aplicación del "método práctico" basado en la observación y en las prácticas modernas de mensura, las actividades de cada partida, las características topográficas e hidrográficas y la descripción de animales "raros" de interés para la moderna historia natural (PENHOS, 2005). En contraste con las empresas de reconocimiento realizadas en los siglos precedentes se consideraba central la utilización de métodos específicos de medición y observación como vehículo de conocimiento. En relación con esto último se buscaba que la indagación se realizara rigurosamente y diera como resultado la obtención de información detallada y útil para los fines políticos y económicos propuestos. Los viajes y exploraciones realizados bajo el reformismo borbónico actualizaban la dominación imperial a través de la presencia de expertos autorizados que hacían las veces de embajadores e informantes al mismo tiempo que contribuían a la consolidación de un cuerpo de experiencia y conocimiento empírico relacionada con las líneas científicas de la época que llevaban al deseo de publicar los resultados en un carrera personal y editorial. Esta faceta secular y múltiple “convirtió al viajero en un espía, al crítico moral en un educador y al geógrafo en un ideólogo" en donde la expansión europea se "confundía con el mismo acto de conocer" (CICERCHIA, 2000, p. 2-3).

Los emisarios borbónicos en su faceta científica estaban deseosos de demostrar la capacidad de los métodos de conocimiento sobre lo que era el tema central de la política expansionista europea, la posesión, la ocupación o reconquista de territorios, considerados "vírgenes" o desaprovechados por sus enormes potencialidades o estratégicos por sus vías de acceso y bienes comerciales, en clara competencia con otras potencias ${ }^{12}$. Asimismo, los viajeros en su rol de comisionados estaban abocados a dar cuenta de su profesionalidad, eficiencia, neutralidad y obediencia en base a un modelo de funcionario que se buscaba imponer contra la imagen "corrupta" e ineficiente de las administraciones precedentes ${ }^{13}$. Finalmente, se buscaba dar cuenta que el universo tenía una dimensión controlable y aprehensible lo que trascendía a la historia natural y a sus clasificaciones botánicas para penetrar en la esfera de las relaciones sociales y políticas, pretendiendo elaborar un mapa del mundo donde todo tenía un orden y estaba exento de conflictos. La literatura de viajes "produjo el resto del mundo" para el público europeo, y una forma de conciencia global

12 La Corona buscaba consolidar su presencia en aquellos territorios que habían adquirido una importante dimensión geo-estratégica así como establecer límites exactos y conocer cuales eran las capacidades que tenían esas tierras para ser integradas a los proyectos comerciales, administrativos y militares auspiciados por el reformismo borbónico (LAZARO AVILA, 1996).

13 Bajo el gobierno borbónico comenzaron a difundirse valores como la capacidad, el empeño y el talento y, en consecuencia, muchos individuos que no provenían de la nobleza o de la elite se incorporaron a la burocracia imperial. 
planetaria y en este sentido los textos etnográficos fueron un medio en que los europeos se representaron a sí mismo y a los otros construyendo marcos fijos de referencia e interpretación sobre el lugar ocupado por cada uno en el movimiento de fortalecimiento político de las potencias económicas respectivas (PRATT, 1997, p. 23).

Estos esquemas de conocimiento y reconstrucción del mundo en sus diversas dimensiones tendrán una clara expresión en las narraciones escritas por los comisionados enviados al Río de la Plata como parte de la Expedición de Límites a la América Meridional o por administradores locales imbuidos de los nuevos marcos ideológicos. Sujetos como Félix de Azara, Diego de Alvear y Gonzalo de Doblas, a pesar de su diferentes formaciones y experiencias, mostraron una comunidad de pensamiento que implicó una puesta en escena de las potenciales de la región misionera, en la que estaban asentados treinta pueblos guaraníes, en relación con una ideología y objetivos concretos, predestinando su rumbo y su transformación en función del poder idealizado dado a la educación, a la industria y al comercio, que descartó toda consideración de las prácticas y concepciones locales. Lo que prevaleció en las relaciones de Azara, Doblas y Alvear fue una mirada que apuntaba a describir ciertos aspectos relacionados con los recursos naturales, la geografía y la población para luego presentar consideraciones centradas básicamente en las formas de revertir la situación de "decadencia" descripta para los pueblos guaraníes, sus tierras de cultivo y sus recursos ganaderos y con ello garantizar una explotación eficiente para las arcas del Estado. No obstante, al representar directamente los intereses del soberano español, en su vertiente absolutista y centralista, la política esbozada por los comisionados y demarcadores se enfrentará contra actores particulares, administradores o gobernadores locales. Asimismo algunos de ellos se involucraron en las redes de poder, comercio y sensualidad que exponía el espacio geográfico y social recorrido (LUCENA GIRALDO, 2003, p. 34).

Los relatos construidos sobre marcos utópicos, ideales y etnocentristas distanciaron a sus observadores de cualquier método que pretendiese un conocimiento o una aproximación al conocimiento de lo local desde la interacción de diferentes marcos culturales. En este sentido, el esfuerzo por disolver los signos de las subjetividades terminaron por construir aparatos de escritura más o tan poderosos que sus predecesores, las crónicas morales, al estar enmascarados de neutralidad, al mismo tiempo que inútiles, en relación a las funciones de dominación del poder borbónico sobre los ámbitos locales. La construcción de la realidad bajo retóricas basadas en una linealidad cercana a liviandad, en contraposición a la narrativa centrada en demostrar las hazañas, los padecimientos y sufrimientos, buscaba garantizar desde la 
intelectualidad y la escritura el proyecto de reconquista territorial, económica y política signada por el reformismo borbónico. El encuentro entre ciertas concepciones sobre el territorio, sus delimitaciones y potencialidades, volcadas claramente en estas escrituras que hacían las veces de tratados generales concebidas desde marcos teóricos casi dogmáticos, mostró los limites y los alcances de estas narrativas en su dimensión política y cognoscitiva expuestas por diferentes actores durante su estadía en estas recónditas pero atractivas tierras.

\section{"La provincia de misiones de indios guaraníes" en la narrativa expedicionaria}

En primer lugar y ante todo las partidas demarcadoras debían reconocer los parajes seleccionados y establecer los mojones con la concurrencia simultánea de los comisarios portugueses, según los accidentes naturales determinados en el documento del Tratado para marcar los límites entre las posesiones coloniales de ambos dominios ibéricos. Si bien las demarcaciones comenzaron a principios de 1782, en el Río de la Plata la tarea de las comisiones no empezó hasta el año 1784. Una vez iniciados los trabajos la partida a cargo del comisarios Félix de Azara recorrió las primeras vertientes del Paraná y del Paraguay y delegó la tarea de explorar el Paraná hasta Buenos Aires, el Uruguay desde Buenos Aires hasta su Salto y el Paraguay en su unión con el Uruguay. Por su parte, la expedición al mando del Diego de Alvear recorrió el curso el Paraná desde el Salto Grande hasta el pueblo de Candelaria, actual provincia de Misiones (AZARA, 1943, p. 3-4). Ambas comitivas entraron en contacto con las misiones de indios guaraníes y con el territorio en que estos estaban localizados. Habían pasado diecisiete años después de la expulsión de los jesuitas y mucho había cambiado desde entonces. Los demarcadores, a diferencia de aquellos que realizaron su tarea tras la firma del Tratado de Madrid (1750), debían garantizar las gestiones de Límites que implican la conservación de todo el territorio de las misiones, Colonia de Sacramento y parte del territorio del actual Río Grande do Sul en manos de la Corona española. 
Figura 1- MAPA: Las Partidas demarcadoras de Límites (1777-1802)

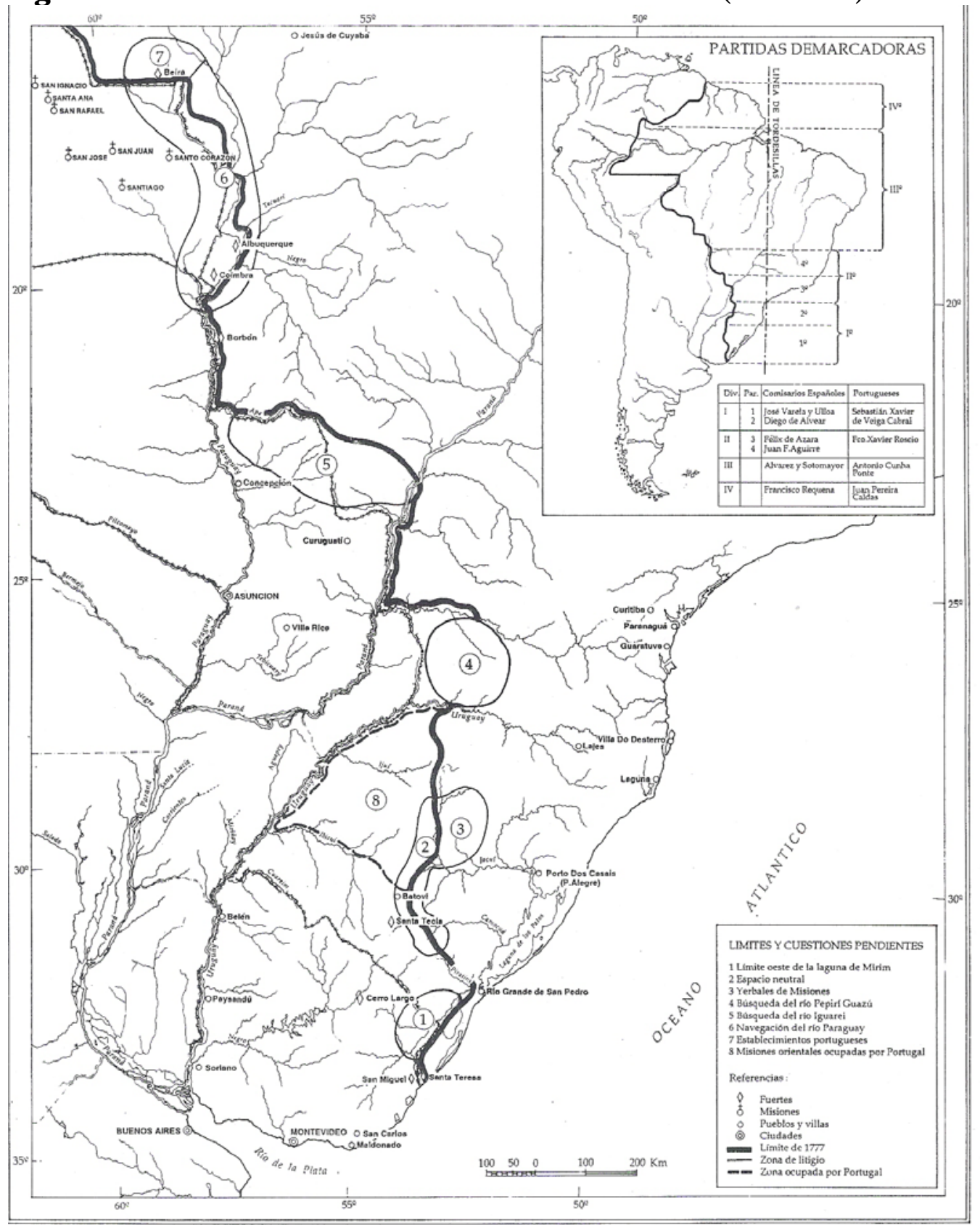

Fuente: Maeder y Gutiérrez (1995, p. 75)

Además de la tarea demarcatoria propiamente dicha que los comisarios debían realizar, junto con la elaboración de planos y mapas, las instrucciones sugerían la inclusión de una "Colección de observaciones de Historia Natural sobre los tres grandes Reinos de la Naturaleza, Animal, Vegetal y Mineral distribuidos según sus clases, Órdenes, Géneros, Especies y Variedades”. No todos estaban capacitados ampliamente para un estudio riguroso del tema, como era el caso de Diego de Alvear para quien era "un punto ajeno a nuestra profesión" al "que solo podemos entrar por un efecto de curiosidad que insinúan las instrucciones si nuestras fuerzas alcanzaren". 
Sin embargo, la mayoría conocía el sistema establecido por Linneo ${ }^{14}$ y algunos en particular, tales como Alvear, lo consideraban como el "más celebre de los naturalistas modernos"15. En consecuencia los comisarios incluyeron en sus relaciones, memorias e informes observaciones y notas en el orden de la historia natural con diferente grado de precisión, compromiso y dificultad. Por último, la elaboración de un diario de viajes era un requisito general para aquellos capitanes o tenientes de Navíos y Fragatas. Así lo expresaba Diego de Alvear ${ }^{16}$ :

Las ordenanzas de Marina imponen a los oficiales de la Real Armada la obligación de presentar un diario al regreso de cada uno de sus viajes. La comisión de Límites no hace sino subir de punto los grados de esta necesidad, haciendo más pesado el cargo con circunstancias que lo dificultan y complican, al paso que en ella los medios y proporciones están más distantes. Tenemos pues lugar de esperar que nuestro trabajo será recibido con indulgencia y excusadas nuestras faltas y descuidos dando por sentado que no serán pocos ${ }^{17}$.

En el lado casi opuesto se encontraba Félix de Azara quien, como un investigador atento y solitario, afirmaba haber superado las instrucciones dadas realizando durante veinte años viajes por el interior del territorio y redactando apuntes sobre temas diversos que incluían aspectos geográficos, botánicos y sociales, entre otras $\operatorname{cosas}^{18}$. En palabras del mismo Azara:

14 Carl Linnaeus (1707-1778) en su "Sistema de la Naturaleza" (1735) dividía todas las cosas vivientes en especies y géneros sentando las bases para las futuras clasificaciones y legitimaciones de las subdivisiones jerárquicas del "género humano" (WADE, 2000).

15 Diario de la Segunda Partida de la Demarcación de Límites entre los Dominios de España y Portugal en la América Meridional por el comisario de ella el Teniente de Navío de la Real Armada Don Diego de Alvear y Escalera. Archivo General de la Nación (AGN). Sala VII, Colección Biblioteca Nacional, documento 36, foja 33.

16 Diego de Alvear nació en Córdoba, España, en 1749. Cursó estudios en centros jesuitas y realizó la carrera militar hasta alcanzar el grado de Brigadier. Así formó parte de la expedición de Pedro de Ceballos que salió de Cádiz en 1776 y se apoderó de la Isla Santa Catalina en 1777. Por el Tratado de Límites del 1 de octubre de 1777 fue nombrado primer comisario y jefe astrónomo de la segunda división, mientras se esperaba a los demás comisarios que llegaran de España. Como comandante exploró el río Uruguay aguas arriba en canoa y a pie, lo que ocasionó muchas pérdidas. Realizó trabajos de demarcación hasta el 1801 y se embarcó hacia Europa en 1804.

17 Diario de la Segunda Partida de la Demarcación de Límites entre los Dominios de España y Portugal en la América Meridional por el comisario de ella el Teniente de Navío de la Real Armada Don Diego de Alvear y Escalera. Archivo General de la Nación (AGN). Sala VII, Colección Biblioteca Nacional, documento 36, foja 34.

18 Félix de Azara nació el 18 de mayo de 1742, en Barbuñales, provincia de Huesca, en el seno de una familia ilustre e influyente. Estudió en la Universidad de Huesca y más tarde en la Academia Militar de Barcelona. Realizó trabajos de ingeniería en ríos y fortificaciones españolas. Asimismo, sirvió en el regimiento de infantería de Galicia y en 1775 participó en la guerra contra Argel en la cual fue herido durante el desembarco. Una vez en España fue nombrado teniente de Ingenieros y capitán de Infantería, con el título de ingeniero extraordinario. Participó como miembro destacado de La Sociedad Económica Aragonesa y en 1780 ya con el grado de teniente coronel de Ingenieros recibió la orden de traslado a América del Sur para cumplir con las tareas de demarcación originadas por el Tratado de San Ildefonso. 
El año de 1781 me embarqué de orden del rey en Lisboa y arribé al Brasil, de donde pasé luego al Río de la Plata. Allí me encargó el gobierno muchas y grandes comisiones, que no es el del caso especificar; bastando decir, que para desempeñarlas tuve que hacer muchos y dilatados viajes, y que hice voluntariamente otros con el objeto de adquirir mayores conocimientos de aquellos vastos países. En todas mis peregrinaciones observé siempre la latitud geográfica al medio día y a la noche por el sol y las estrellas con un buen instrumento de reflexión y horizonte artificial (AZARA, 1943, p. 3)

Félix de Azara tras ser nombrado primer comisario de la Tercera Partida Demarcadora fue destinado a Asunción, ciudad base de su viajes y exploraciones. Durante los trabajos realizados en las proximidades de las misiones guaraníes de los ríos Paraná y Uruguay apeló a diferentes fuentes provenientes de funcionarios y administradores, como así también de autoridades nativas de las misiones con las que intercambió información y apreciaciones sobre la situación administrativa, la historia precedente y ciertos rasgos relacionados con la distribución y características observadas por él sobre la población local. Fue bajo estas circunstancias que entró en contacto con Gonzalo de Doblas, teniente del gobernador del Departamento de Concepción a cargo de los pueblos de Concepción, San J avier, Santa María La Mayor, San J osé, Apóstoles y Mártires, fundados originalmente por los jesuitas junto a los guaraníes ${ }^{19}$. Frente a su experiencia en la región de misiones, Félix de Azara le encargó "una relación de noticias" para incorporar a su obra y Doblas cumplió con el pedido ampliamente ${ }^{20}$. En poco tiempo, el teniente de gobernador de Concepción le entregó un manuscrito de importantes dimensiones titulado "Memoria histórica, geográfica, política y económica sobre la provincia de misiones de indios guaraníes" y fechado en Concepción, el 27 de septiembre de 1785. A este círculo se sumó Diego de Alvear y Escalante, primer comisario y jefe astrónomo de la Segunda Partida encargada de delimitar y examinar el curso del Paraná desde el Salto Grande hasta el pueblo de Candelaria, en el territorio de Misiones. Este comisario contribuyó también con su narrativa sobre Misiones con su “Relación geográfica e histórica del territorio de las Misiones", fechada en 1791. Estas narrativas se inscriben y aportan información dentro de un paradigma político nuevo y a la vez imponen sus visiones particulares en relación con las descripciones del espacio misionero. Interesa entonces ver cómo estos tres hombres de origen español formados dentro de instituciones reformadas y bajo imperativos políticos fuertes y determinantes

19 Gonzalo de Doblas nació Iznájar, Andalucía, en 1744 dentro de una familia distinguida. Luego de abandonar la carrera del comercio se dedicó al servicio público. Pasó a América en el año de 1768 y en 1781 fue nombrado Teniente de Gobernador del departamento de Concepción.

20 Carta de Gonzalo de Doblas al Señor Don Félix de Azara Capitán de fragata de la Real Armada y comandante de la tercera partida de la demarcación de límites con Portugal, por la provincia del Paraguay (ANGELIS, 1970, p. 21). 
interpelaron el espacio misionero y cuáles fueron las utopías depositadas en el mismo en relación a las líneas políticas proyectadas en torno a los pueblos de misiones.

En las observaciones, delimitaciones y narrativas mencionadas sobre el espacio misionero es plausible observar la existencia de diferentes intereses o representaciones en torno al ordenamiento social, su clasificación o segregación social o étnica, a las relaciones entre población y medio ambiente, a la explotación de los recursos, a las identidades o sentidos de pertenencia locales o globales entre otras cosas que proyectan utopías en torno a la construcción de un nuevo espacio, en donde se incluye vínculos y roles sociales, modalidades de acción política, económica y cultural (GARAVAGLIA, 1992; HESPANHA, 1993; MÖRNER, 1995). A su vez se parte de códigos de interpelación aprehensibles para un destinatario concreto así como de conocimientos, experiencias o herramientas propias que imprimirán un sello particular a cada una de las narrativas. En términos generales, se apunta al valor de la escritura y su difusión en función del cambio del que tanto Azara, Alvear como Doblas se sentían agentes sustanciales, presentando a los pueblos de misiones como el lugar óptimo para concretar sus aspiraciones reformistas. Para ello, mirando al pasado, contrapusieron sus ideales con el modelo jesuítico previo y sobre eso sentaron las bases del fututo modelo.

En el caso de Félix de Azara, comisario de la Tercera Partida demarcatoria, su percepción del espacio aparece influida casi en su totalidad por los objetivos de la expedición de demarcación y mediada por los nuevos instrumentos de medición utilizados así como por las etapas en las que realizó sus observaciones y el encuadre dado a las mismas (PENHOS, 2005, p. 145). En este sentido el relato, escrito a partir de los viajes realizados por la cuenca del Plata, estuvo marcado por una mirada que no refleja tanto la penetración de lo local en la subjetividad del narrador sino un objetivo claro que es aprehender el espacio en términos cuantitativos y cualitativos, medir, caracterizar, clasificar y ordenar el mundo observado de una forma pedagoga y concisa, práctica y moderna. Dentro de un paradigma vigente donde el clima y la geografía se consideran influyentes en la variabilidad de la naturaleza como de las sociedades humana es que Azara comienza su “Descripción e Historia del Paraguay y del Río de la Plata" detallando el clima y los vientos desde la cordillera en su limite occidental hasta la costa patagónica por su límite oriental llegando al Río de la Plata²1. Así luego de una

21 Las antiguas teorías sobre las determinaciones medioambientales cobraron vitalidad a partir de las formulaciones de la zoología geográfica, cuyo principal exponente fue el francés Georges Louis Leclerc (Conde de Buffon, 1707-1788). Lo novedoso de su aporte, entre otras cosas, fue el estudio de las especies animales en su ambiente geográfico como fenómenos del mundo físico y no de 
extensa y minuciosa descripción sobre el tema concluye que "por lo relativo a la salud, puede tenerse por cierto que no hay en el mundo países más sanos que todos aquellos" para luego abocarse al mundo mineral, vegetal y animal, a las "tres castas" de la época indios, pardos y españoles y cerrar con reflexiones y relatos sobre la conquista y el gobierno de los jesuitas (AZARA, 1943, p. 14). No obstante, si bien parte de la idea del determinismo medioambiental encuentra que este no parece dar respuesta a la diversidad intergrupal que observa en estas regiones. Azara escribe "me ha parecido anotar aquí algunas reflexiones obvias sobre mis indios silvestres" y entre ellas afirma:

Habitando todas mis naciones una misma llanura, donde hay los mismos vegetales, pájaros, y cuadrúpedos iguales en formas y magnitudes, es cosa muy extraña la diferencia que hay de unas a otras en los idiomas, estatura, fuerzas y soberbia, siendo las más de ellas indomables y las restantes pusilánimes en extremo. Los guaraníes eran idénticos en todas partes por más distantes que estaban unos de otros (AZARA, 1943, p. 162).

Al caracterizar a la población de la regiones recorridas o registradas a lo largo de la cuenca del Plata como a sus formas de gobierno si bien entra en el terreno de la escala clasificatoria de la época Azara combina en sus reflexiones y en su forma de captar y clasificar la diversidad diferentes teorías e ideologías que consideran desde los factores deterministas como era medio ambiente, la alusión a las cuestiones físicas y morales como ejes de descripción, hasta la comparación cultural propia del preevolucionismo. A su vez, por razones prácticas e utilitaristas encuentra en el mestizaje una vía idónea para sus proyectos políticos. Al respecto afirmaba que "de aquí puede deducirse, no solo que las especies se mejoran con las mezclas, sino también que la europea es más inalterable que la india, pues a la larga desaparece esta y prevalece con ventajas aquella" (AZARA, 1943, p. 192). Las expectativas depositadas en las ventajas del blanqueamiento propias del universo mental europeo de la época tenían en Azara un vínculo directo con las potenciales o réditos que se esperaba de esta población en relación con los proyectos económicos y productivos destinados para estas regiones. El mundo local entraba en la lupa en la que subyacían fines claros, cumplir de forma eficiente y rápida con los mandatos políticos y científicos impuestos e imponer modificaciones en las formas de gobierno, en los usos y en la explotación de los recursos, en los círculos comerciales así como en el destino de la población indígena en

Dios. Es sobre la línea de Buffon, mas que sobre la de Linneo, que Azara estructura algunas de sus observaciones y descripciones, tras haber conocido su obra en Buenos Aires (PENHOS, 2005). 
relación con su rendimiento. Dentro de la misma línea el teniente del Departamento de Concepción, Gonzalo de Doblas, le escribía a Azara al entregarle su manuscrito:

\begin{abstract}
Algo dilatado será este papel; pero de todas las noticias que yo amontonaré en él, podrá usted elegir las que le sean más oportunas, y desechar las menos necesarias: y si entre ellas encuentra usted algunas que puedan ser útiles al servicio del rey, bien de estos naturales o engrandecimiento del estado puede usted valerse de ellas en los términos que tenga por conveniente: pues me compadezco de ver una provincia tan fértil como ésta, y que ni sus habitadores, ni el rey disfruten las conveniencias ni adelantamientos que es está ofreciendo 22 .
\end{abstract}

Para Doblas la provincia de Misiones contaba con enormes recursos para proveer una mejor calidad de vida a sus habitantes y mejores ingresos para la Corona. Doblas describía como en sus bosques

así en lo que se hallan en las alturas, como en los valles y quebradas, se encuentran muchas maderas de varias especies, a propósito para la construcción de embarcaciones, fábricas de casas y muebles: algunas bastante preciosas [...] La calidad de la tierra es gredosa [...] generalmente fértil, principalmente en la falda de los cerros cerca de los montes y en los rozados; y sin embargo de lo poco con los naturales cultivan la tierra para sembrarla, recogen abundantes cosechas (DOBLAS, 1970, p. 24-25)

\title{
Asimismo enfatizaba en los recursos no explotados al señalar que
}

[...] inmediato al Paraná, en una y otra banda, cerca de los pueblos de Candelaria y Santa Ana hay exquisito cobre, pero aunque se trabajó después de la expulsión fueron abandonadas, porque no alcanzaban las utilidades a sufragar los costos y aunque se asegura que las hay de azogue y de otros metales, hasta ahora no he visto prueba de su existencia (DOBLAS, 1970, p. 26-27).

En relación a sus proyectos urbanísticos afirmaba que "en toda la provincia hay canteras de piedra para edificios, muy dóciles de labrar y de mucha consistencia para permanecer" y como prueba de su visión optimista y convocante se atrevía a afirmar que "en esta provincia son muy pocos los insectos que incomodan a los hombres" (DOBLAS, 1970, p. 26-27). De esta forma, al redescubrir América desde un fin netamente utilitarista, forzando la falta de asombro y enfatizando en el nivel de las

\footnotetext{
22 Carta de Gonzalo de Doblas al Señor Don Félix de Azara Capitán de fragata de la Real Armada y comandante de la tercera partida de la demarcación de límites con Portugal, por la provincia del Paraguay.
} 
certezas Doblas también ponía el acento en la población reducida como recurso fundamental para dar vida y movimiento a sus nuevas utopías.

De la misma forma que Doblas, aunque con una vertiente menos crítica hacia el pasado jesuítico dada su formación, el comisario de la Segunda Partida Diego de Alvear reparó en particular en el espacio misionero por su disposición de población potencialmente productora o proveedora de fuerza de trabajo y por la fertilidad y diversidad de recursos. Al describir las condiciones de los treinta pueblos de misiones afirmaba que

La situación en general de estos pueblos, sobre los dos grandes ríos Paraná y Uruguay, no puede ser más excelente. El terreno es fertilísimo para toda clase de producciones de cuanto puede conducir a una vida cómoda y agradable, y contribuir al fomento del comercio e industria (ALVEAR, 1970, p. 706-707).

Alvear, a su vez, especificó los recursos y cultivos de cada pueblo a constituirse en ramo de comercio para sustentar a otras provincias y activar un intenso mercado interno con lógicas impositivas y sin privilegios particulares. En todos los casos recomendaba qué bienes comercializar e insistía en la diversidad y en la falta de explotación de algunos productos. Por ejemplo, tras hablar del Departamento de Santiago señaló todo aquello que podría ser comercializado e implicar un

[...] renglón de considerable entrada para estos pueblos [...] más que todos los bálsamos, resinas y plantas medicinales de que abunda el país, y de que no se hace uso, todas estas cosas y otras muchas tiene buen despacio por todas partes, con preferencia en la capital, y vendrían a ser con el debido esmero y aplicación perenne manantial de riquezas para toda la provincia (ALVEAR, 1970, p. 714).

Desde la mirada "industriosa" de Alvear se intuye un ansia por extraer la mayor cantidad de recursos en su dimensión productiva, extractiva o reproductiva que queda expuesta, por ejemplo, al describir la actividad en el monte:

Los montes en este gran río son, como hemos dicho, tan considerables que no hay que tener miedo que los agoten antes por el contrario la tala o poda que hace a los árboles, les sirve de gran beneficio, la yerba se refina, adquiere mayor fragancia y suavidad, y el peinar y abrir los montes conducir no poco para la cría de buenas maderas, y plantas medicinales y útiles. No se alcanza porque se pone coto al beneficio de tan ricos minerales. Otra nación más industriosa hubiera sabido extender a Europa el uso de esta yerba, cuyas ventajosas propiedades no ceden a las del te y café; y hasta el modo de servirla, con mate y bombilla, es mucho más fácil y pronto, y no necesita de aquellos embarazosos aparatos y juegos de loza de China (ALVEAR, 1970, p. 720). 
La falta de límites al comercio lindaba con una ausencia de una política proteccionista sobre el agotamiento de los recursos, tema que si era observado en relación con el ganado cimarrón de la región. En este caso, Alvear marcaba la necesidad de establecer una política más conservadora ya que en relación con el "ganado silvestre" afirmaba que

[...] con el pretexto de hallarse en tierras realengas y las otras partes con el de haber salido de las suyas, todos alegan derecho a este ganado. Más antes que los tribunales decidan este célebre litigio, sino se ataja aquel inconveniente de las vaquerías, desaparecerá la alhaja, y el estado perderá uno de los más pingües ramos de su comercio envidiado siempre por las otras naciones (ALVEAR, 1970, p. 716).

Esta política de fomento indiscriminado de la producción dentro de la provincia misionera, combinada con políticas de exclusividad en la explotación de recursos como el ganado, guardaba a su vez una política de interacción con el medio y sus habitantes basada en la rentabilidad absoluta, una rentabilidad despojada de artilugios en la relación entre la Corona y sus súbditos, sin retóricas de amor, protección y cuidado, propias del la esfera monárquica precedente (HESPANHA, 1997). Dentro de esta óptica su visión sobre el espacio misionero se resumía de la siguiente manera

\begin{abstract}
Si damos ahora valor a la administración de justicia, teniendo los indios privilegios de menores, y gozando de entera libertad de derechos y costos en los tribunales del reino, y estimamos lo que puede valer la conservación y defensa de sus países en tiempos de guerra, veríamos que las misiones, en el píe que se hallan, son muy gravosas al estado, y que solo se mantienen para aumento de la cristiandad (ALVEAR, 1970, p. 721).
\end{abstract}

Ni la conversión, ni el aumento de súbditos cristianos para la Corona, ni la protección sobre la población y sus sistema de pueblos, ni el pago de un tributo o diezmo, ni su antigua función como milicias se constituían en razones suficientes para sostener las misiones en el estado actual denominado "sistema de comunidad"23. Básicamente, se oponía a la "comunidad de bienes" que, según él, mantenía la producción en niveles de subsistencia como al comercio monopolizado en pocas manos. Alvear, inmerso en esa red de comercio, proyectaba sobre ese espacio re-descubierto un

23 Define comunidad como un "método de policía” donde "cada pueblo es considerado como una casa de familia y toda la provincia un solo pueblo" (ALVEAR, 1970, p. 699). 
manantial para el nuevo mercantilismo capitalista, con circulación de dinero, sin restricciones impuestas por la administración general de Buenos Aires, basado en contratos de comercio formales, sin leyes secas a venta de licores y caldos y con libre entrada a los comerciantes en los pueblos de misiones. Dentro de está lógica, consideraba al "comercio interior por muchos títulos más ventajoso y preferible al exterior, a qué solo se debe atender después de haber dado al otro su vigor y actividad" (ALVEAR, 1970, p. 725). Alvear imaginaba un paraíso de libertades comerciales aunque estructuradas bajo las lógicas del mercado capitalista de la época, asociado a la racionalidad, capacidad y ventajas individuales, pero sosteniendo los derechos extractivos del estado colonial, sin inversión ni costo alguno. Alvear resumía su postura de tal manera:

\begin{abstract}
Además de esto, los pueblos no deben ser únicamente para ellos mismos: deber ser útiles al estado de que recibieron el ser que tienen, y contribuir a la común felicidad de sus compatriotas: y este gran comercio a que se aspira este gran monopolio, trae consigo todas las nulidades, todos los inconvenientes de las compañías exclusivas, mucho más peligrosas en todas las Américas: y más cuando se trata de una provincia que es un imperio (ALVEAR, 1970, p. 726).
\end{abstract}

En la percepción sobre el espacio misionero como un potencial imperio de riquezas y fuentes de materias primas, que se conquistaría con políticas precisas que respondían al engrandecimiento del estado y a la anulación de todos los privilegios y limitaciones, entraba en juego la crítica al sistema de gobierno llamado de comunidad como el "escandaloso arreglo de costumbres" que imperaba según Alvear en estos "países tan remotos" (ALVEAR, 1970, p. 583-727). Mientras el se posicionaba desde el lugar de observador en donde la "fidelidad a nuestro empleo, y el amor a la patria nos han obligado a hablar con claridad en esta materia" no hay pocas razones para suponer que sus intereses directos en el mercado interno no eran pocos y desafortunados.

Por su parte, Gonzalo de Doblas y Félix de Azara también asentaban una crítica sobre el actual estado de las misiones y especialmente sobre el "régimen de comunidad" que había sido confirmado por el gobernador Francisco de Paula Bucareli y Ursúa, en 1768, en sintonía con el régimen jesuítico heredado, y sostenido desde entonces por la nueva administración. Al respecto Doblas en tanto administrador de Misiones describía las características del sistema: 
El gobierno y dirección de toda la comunidad se depositó en el corregidor y el cabildo, ayudados y dirigidos del administrador español, y sujetos en un todo al gobernador o teniente a quienes correspondiese el inmediato mando, dándose reglas en la misma ordenanza para el mejor manejo de los bienes y sus adelantamientos; como también para desterrar de los naturales la rudeza y abatimiento en que habían sido educados, infundiéndoles ideas política y racionales, que les excitase el deseo de una felicidad que no conocían, y a que les está convidando la fertilidad de sus terrenos; con otras muchas y sabias reglas que allí se establecen . Para que el sobrante de los frutos y efectos que se recogen y benefician en estos pueblos se expidiesen con aquella estimación más ventajosa a los pueblos, se estableció un administrador general en la ciudad de Buenos Aires dándole reglas equitativas y mus útiles para que, puestos los frutos y efectos en una sola mano, nos perdiesen la estimación, como sucedería distribuidos en las de muchos, y que por mano de éste se surtiesen los pueblos de lo necesario, pagasen los reales tributos según los padrones, a razón de un peso por cada tributario, y enterase a la iglesia los diezmos que están regulados a 100 pesos cada pueblo (DOBLAS, 1970, p. 42-43).

Doblas, como parte de la administración misionera, consideraba que "pareció los más conveniente," en su momento, dejar a los pueblos "sujetos a la misma comunidad, como lo habían estado: hasta que con el tiempo se hiciesen más capaces". Sin embargo, proclamaba el cambio:

Estos pueblos, desde su reducción, se han mantenido y mantienen en comunidad; y aunque este método de gobierno sería útil a los principios, después no ha servido en mi concepto sino a impedir los progresos de policía y civilidad: los que subsistirán desde mismo modo, entre tanto no se mude de gobierno, dando entera libertad a los indios como dicta la naturaleza (DOBLAS, 1970, p. 35).

Doblas depositaba de esta manera en la herencia de un pasado y un sistema contrarios al "aumento y felicidad de los pueblos y naciones" la responsabilidad de las incongruencias presentes (DOBLAS, 1970, p. 43). A su vez, si bien como parte de las ideas que asociaban la geografía y el temperamento con las cualidades de los individuos, Doblas aludía a las capacidades de los "naturales" dispuestos en los pueblos de misiones y al rol de la educación como medio de transformación en productores agrícolas y su adaptación a las necesidades del Estado. Al respecto escribía:

no negaré que el temperamento y alimentos pueden influir algo en la robustez y disposición del cuerpo, y hacerlos más o menos activo según sus cualidades, y mucho más puede influir en mi concepto la educación por el cual se imprimen en el ánimo las ideas que determinan sus operaciones; pero negaré siempre que estos sean unos estorbos incapaces de vencerlos, como muchos piensan. Convendré si en que costará trabajo, pero no en que es imposible (DOBLAS, 1970, p. 75). 
El valor transformador dado a la educación significaba la posibilidad de depositar en los guaraníes de los pueblos la totalidad del proceso laboral productivo contra la aplicación de políticas inmigratorias de diferente índole para contar con mano de obra libre ${ }^{24}$. Por el contrario según Doblas lo que había determinada la "incapacidad" de los indios para la producción, la acumulación, la comercialización y el trabajo

era el haberlos tenido sujetos a comunidad, y no haberles inspirado otras ideas que las de la sumisión y obediencia, tratándoles como a hijos de familia, menores de edad, no pudiendo ilustrar sus entendimientos, para que desde luego aprendiesen a trabajar para ellos, tratar y comerciar unos con otros con sus frutos y efectos, conchabándose los de menos habilidad, con los más expertos y laboriosos, y a verificar todos aquellos medios y arbitrios que se practican entre gente civilizada, tratando y comerciando, no tan solamente entre sí, sino también con los forasteros (DOBLAS, 1970, p. 43).

Frente a esta situación no solo Doblas sino también Azara y Alvear ponían en el centro de la escena la herencia de un sistema desfasado y decadente como era para ellos la "comunidad de bienes". A este régimen atribuían la falta de libertad, incentivo al trabajo, la ociosidad improductiva así como los abusos, fugas, deserciones y corrupción de los administradores locales. Para ellos la reversión de la situación actual de los pueblos pasaba por una reformulación del gobierno y la economía que incluía el sistema laboral y la propiedad de la tierra. El problema de fondo era que para direccionar las potencialidades de la región hacia la producción y el comercio era necesario disponer de mano de obra libre y el sistema en estas condiciones lo impedía porque "ni aún se puede conchabar a un peón, sin dar cuenta al administrador (de misiones) porque están sujetos a la comunidad, ni los indios saben vender su trabajo" (DOBLAS, 1970, p. 55). Operaba a su vez en los indios, según Doblas, en la ausencia de incentivo a producir más de lo necesario, la falta de premio y la extensión del castigo. En relación con la acumulación y distribución "racional de los bienes" de comunidad Doblas afirmaba "es increíble lo que se desperdicia y se pierde" en personal, fiestas y regalos. Las prácticas de reciprocidad y hasta de clientelismo eran puestas en tela de juicio en una coyuntura en que la política se volvía más abstracta y práctica. Este giro estaba ligado al ideal borbónico de funcionarios eficientes, virtuosos y fieles al Rey. Modelo dentro del cual Doblas buscaba ubicarse al señalar su intervención "tan

24 Las relaciones entre raza e historia en América colonial y republicana y el rol dado a la educación, a la migración, la política y la económica, entre otras cosas, han sido analizados pormenorizadamente en los diferentes trabajos compilados por Marisol de la Cadena (2007). 
cumplidamente" como teniente de gobernador en todas las situaciones en que había habido discordia por la administración de bienes y abusos (DOBLAS, 1970, p. 69).

Azara, por su lado, aludía también a la ausencia de una racionalidad en la distribución de los bienes, en la sujeción y dominación de la población de los misiones y a la falta de educación de la misma pero hacía una expresa defensa del colonialismo español al afirmar que "las leyes eran buenas" el problema era que no se respetaban e insistía en que la "desgracia de los indios" no debía atribuirse al gobierno de los españoles sino al "gobierno de comunidad" (AZARA, 1941, p. 102-103). En este sentido, Azara no hacía una crítica al régimen de administración aplicado después de la expulsión de los jesuitas sino que adjudica ciertas irregularidades a causa de que los administradores tomaban

[...] a los establecimientos como una cosa que solo pueden disponer un tiempo limitado y únicamente procuran aprovecharse del momento presente. De aquí que ellos no alimentan ni visten a los indios tan bien como otras veces y los fatigan de trabajo. El tesoro real no saca nada, ni nunca sacó nada de estos pueblos (AZARA, 1941, p. 109-110).

Por su parte, afirmaba que no puede

[...] ocultarse que después de la salida de los jesuitas algunos indios se han civilizado algo y gozan de cierto bienestar debido a sus comercios y a su ganado. Hablando en general han progresado algo hacia la civilización; se visten a la española y adquieren cierta pequeña propiedad; pero como no tienen el especial cuidado de los jesuitas la mitad de los pueblos está desierta y los indios se entienden por todas partes en libertad mezclándose con los españoles (AZARA, 1941, p. 110).

Si bien destacaba el problema de los abusos y la malversación de los administradores el ideal de organización expresado por Azara se construía en gran medida contra el modelo jesuítico. En particular privilegiaba el intercambio en todos sus niveles contra la política segregacionista aplicada por los misioneros. Azara imaginaba las misiones como un territorio continuo dentro de los dominios del gobierno español, intensamente vinculado a la metrópoli, en contraste con el complejo jesuita autónomo, cerrado y aislado en sí mismo donde en teoría la comunicación había estaba intensamente controlada por el cierre de las avenidas de los pueblos, la existencia de profundos fosos, estacadas, guardias y centinelas. Concebía entonces un espacio donde la población gozara de libertad mezclándose sin restricciones en oposición a lo supuestamente ocurrido en los tiempos jesuíticos. Al remitirse a la densidad demográfica de la población de los pueblos afirmaba: 
Puedo probar por los registros y catastros originales de la fundación de cada pueblo, sacados de los archivos y comparados con los actuales que los Indios originarios aumentaron aunque una infinidad se haya convertido a españoles por la mezcla de razas (AZARA, 1941, p. 102103).

De esta forma adhería plenamente al paradigma asimilacionista vigente en relación a la población indígena y proponía líneas concretas de acción. En primer lugar la anulación del sistema de comunidad, la promoción de la industria y la agricultura, la anulación de los abusos de los curas y administradoras y la participación en todo este proceso de hombres hábiles y experimentados.

Por su parte, Doblas también proponía medidas puntuales tales como que permanecieran unidos todos los treinta pueblos, estableciendo límites precisos para esta provincia y designando a Candelaria como capital de ella. Además consideraba que "poniéndose allí los tribunales y demás ministerios que después diré, no tengo duda que en breve se aumentaría su población con los muchos españoles que se avecindarían en ella". Sus proyectos de crecimiento de la provincia y la urbanización tenían como fin obtener el "título y privilegio de ciudad" gracias a las utilidades que saldrían de los pueblos. En relación a las tierras, planteaba la posibilidad de que a los indios se les diera, en caso de demostrar su trabajo continuo, a los tres años título de propiedad para ellos y sus hijos prohibiendo su venta y enajenación y también que "la experiencia les haga saber que no necesitan todos tenerlas; pues con el dinero que adquieren con sus jornales o en otras ocupaciones comprarían lo necesario a otros. En lo que hace al tema defensivo con Portugal en Doblas estaba asociado más a una cuestión comercial que bélica ya que proponía mantener tres cuerpos de tropas veteranas de ochenta o cien hombres con sus oficiales y comandantes, sujetas al gobernador, y destinadas a la fronteras con Portugal desde la fortaleza de Santa Tecla hasta la guardia de San Martín para "impedir así los contrabandos y el abrigo que tienen los portugueses con los minuanes” (DOBLAS, 1970, p. 155, 158, 163 y 172). Doblas como administrador de misiones apuntaba a más a un cambio local y anticipaba políticas y acciones que asomarán con fuerza en la región a lo largo del siglo XIX.

En contraste, Azara reparaba en el espacio misionero dentro de una totalidad mayor con la mirada de un observador más cercano a un viajero. La visión de Azara sobre el espacio resultaba más amplia, lo que se observa en la cuestión defensiva y en sus tareas oficiales al proponer la fundación de poblaciones en la frontera hispanolusitana para detener el avance de los portugueses y, al mismo tiempo, lograr la instalación definitiva de colonos españoles. Sin embargo, las demoras y postergaciones de los portugueses y las incongruencias del gobernador de Asunción llevaron a Azara a 
enemistarse con este y a denunciar, en 1794, que este último tenía correspondencia con los portugueses y que había recibido regalos de excesivo precio ${ }^{25}$. Azara describía su desconcierto de la siguiente manera:

[...] yo no se que ideas deben tener los portugueses para haber tardado la vida de un hombre en resolverse a decirnos que vendrán y después que lo han dicho temo que ha de pasar un siglo presente sin que parezcan por acá [...] dejo aparte lo sensible que me es la consideración de que pasó la mejor parte de mi vida y los años más útiles de ella en este destierro ${ }^{26}$.

Los proyectos de defensa de las fronteras si bien existieron no tomaron fuerza particular en los años de la expedición de límites ${ }^{27}$. Quizá la propia tarea de demarcación creaba la ilusión de un espacio controlado e inspiraba a sus demarcadores y observadores a proponer simplemente proyectos de conservación de espacios particulares contra grupos particulares, como eran los tupís, pero sin riesgo de crear la imagen de desestabilización interna a causa de un ataque fronterizo inminente. Llamativamente en este nuevo contexto la visión sobre las misiones se invierte en relación a las cuestiones de defensa ya que, a diferencia del período precedente donde conformaban un cordón fronterizo para detener el avance hacia otras jurisdicciones coloniales, estas pasaban a ser un espacio privilegiado en sí mismo.

En los nuevos relatos el territorio misionero aparece como el espacio que hay que cuidar por sus potencialidades, estando ahora en potestad absoluta y directa del Rey. Al respecto, Diego de Alvear, en una carta escrita al Virrey Melo, volvió a mencionar a la provincia de misiones y esta vez aludió a la cuestión de defensa contra los ataques de los indios tupies. Allí proponía ciertas ideas "en orden a la total seguridad, conservación y mejoramiento de los pueblos y en general de toda la provincia, sin disputa la más fértil y florida de las del virreinato"28. Para ello consideraba necesario el alistamiento de milicias guaraníes, por un lado, y una intensa colonización criolla, acompañada de una integración poblacional y un fluido comercio, por el otro. De la misma forma que Azara concebía la consolidación de una frontera poblacional y defensiva con núcleos demográficos estables, autosuficientes y activos en

${ }^{25}$ Carta de Félix de Azara al Virrey Nicolás de Arredondo. Asunción, 9 de junio de 1794 (ANGELIS, 1970, p. 432)

${ }^{26}$ Carta de Félix de Azara al Virrey Nicolás de Arredondo. Curuguatí, 30 de julio de 1791 (ANGELIS, 1970, p. 397-398).

27 En 1796, como las actividades demarcadoras continuaban paralizadas por la ausencia de los portugueses, el virrey Pedro Melo de Portugal le confió a Azara el mando de la frontera sur de Buenos Aires y le ordenó reconocer la región habitada por los indios pampas para extender las fronteras españolas en esa dirección (MAZZOLA, 2008).

${ }^{28}$ Sabina de Alvear y Ward. Historia de Don Diego de Alvear y Ponce de León, Madrid, 1891 citada en (MAEDER, 1992, p. 200). 
relación a la comercialización de productos agropecuarios en espejo con el sistema implementado por los portugueses. Sin embargo, el "cientificismo político" volcado en las narrativas se enfrentará con la embestida geopolítica de los portugueses que desistiendo de una línea diplomática pasaron a ocupar por la vía de la guerra el territorio de las misiones orientales, en 1801, e imponiendo por este medio una nueva frontera territorial entre los dominios de ambas Coronas $^{29}$.

Las Memorias, Historias y Relaciones escritas para ser leídas por un público específico, por sujetos como Azara o Alvear, exponían los resultados de una mirada que recuperaba lo local a través de su medición, localización y en función de su potencialidad, accesibilidad y productividad para luego construir su lugar en el mundo en función de una mirada metropolitana sobre lo global. Si bien muchos de los demarcadores o expedicionarios de fines del siglo XVIII y comienzos del XIX pasaran un tiempo largo en América continuaron identificándose y siendo identificados como agentes externos o mediadores en un espacio que no terminaban de hacer suyo. En términos generales el espacio observado fue registrado con una distancia predeterminada, con un ojo científico racionalista y con las emociones puestas en demostrar virtuosismo, eficiencia y fidelidad. Esto conllevó el no recuperar de forma compleja los sentidos, conflictos y dramas de la vida local y cotidiana existentes en el espacio y en la sociedad observada. $\mathrm{Y}$ expuso las contradicciones entre los comisionados borbónicos, los agentes locales y los demarcadores hispano-lusitanos frente a la diversidad de intereses y proyectos políticos que marcaron un conjunto de paradojas en los espacios de la defensa militar, la demarcación, en la comercialización de los bienes de misiones y en el destino de los pueblos guaraníes y su territorio.

\section{Referências}

ALBERT, Salvador Bernabeu. Las utopías y el reformismo borbónico. In: GUIMERÁ, Agustín (Ed). El reformismo borbónico. Madrid: Alianza, 1996. p. 247-263.

ALTURA, Elena. El discurso colonialista de los caminantes (siglos XVII-XVIII). Berkeley: Latinoamericana, 2002.

ALVEAR, Diego de. Relación geográfica e histórica de misiones. In: ANGELIS, Pedro de (Comp.). Colección de obras y documentos relativos a la historia antigua y moderna de las provincias del Río de la Plata. Buenos Aires: Plus Ultra, 1970. p. 579-727.

29 En respuesta Félix de Azara escribió un plan de recuperación del territorio que no tuvo curso concreto. Véase: Informes escritos por Félix de Azara como vocal y en nombre de la Junta Consultiva de Fortificación y Defensa de las Indias sobre varios asuntos del Paraguay y Río de la Plata (1805-1808) (AZARA, 1994, p. 197-200). 
ANGELIS, Pedro de (Comp.). Colección de obras y documentos relativos a la historia antigua y moderna de las provincias del Río de la Plata. Buenos Aires: Plus Ultra, 1970.

ARECES, Nidia. Estado y frontera en el Paraguay: concepción durante el gobierno del Dr. Francia. Asunción: CEADUC, 2007.

AZARA, Félix de. Descripción e historia del Paraguay y del Río dela Plata. Buenos Aires: Bajel, 1943.

AZARA, Félix de. Informes escritos por Félix de Azara como vocal y en nombre de la J unta Consultiva de Fortificación y Defensa de las Indias sobre varios asuntos del Paraguay y Río de la Plata (1805-1808). In: GUIRALDO, Manuel Lucena; RODRIGUEZ, Alberto Barreco (Ed.). Escritos fronterizos. Madrid: CSIC, 1994. p. 197200.

AZARA, Félix de. Viajes por la América Meridional. Madrid: Espasa-Calpe, 1941.

CICERCHIA, Ricardo. De diarios, mapas e inventarios: la narrativa de viaje y la construcción de la modernidad. INTERNATIONAL CONGRESS OF HISTORICAL SCIENCES, 19., 2000, Oslo. Anales... Disponible en:

$<$ http:// www.oslo2000.uio.no/ program/ papers/ s17/ s17-cicerchia.pdf>. Acceso en: jul. 2009.

CICERCHIA, Ricardo. Viajeros: ilustrados y románticos en la imaginación nacional. Buenos Aires: Troquel, 2005.

DE LA CADENA, Marisol (Ed.). Formaciones de indignidad: articulaciones raciales, mestizaje y nación en América Latina. Popayán: Envión, 2007.

DOBLAS, Gonzalo de. Memoria sobre la Provincia de Misiones de indios Guaraníes. In: ANGELIS, Pedro de (Comp.). Colección de obras y documentos relativos a la historia antigua y moderna de las provincias del Río de la Plata. Buenos Aires: Plus Ultra, 1970. p. 23-187.

ESCOLAR, Marcelo. Exploración, cartografía y modernización del poder estatal. International Social Sciences J ournal, Paris, p. 141-142, 1996. Disponible en: <http:// www.unesco.org/ issj/rics151/ escolar.htm>. Acceso en: jul 2009.

GARAVAGLIA, J uan Carlos. Las relaciones entre el medio y las sociedades humanas en su perspectiva histórica. Anuario del IEHS, Tandil, n. 7, p. 41-57, 1992.

GARCIA FRÜHAUF, Elisa. De inimigos a aliados: como parte dos missioneiros repensou o seu passado de conflitos como os portugueses no contexto das tentativas de demarcação do Tratado de Madri. Anais de História de Além-Mar, Lisboa, v. 8, p. 123137, 2007.

GOLIN, Tau. A fronteira: governos e movimentos espontâneos na fixação dos limites do Brasil como Uruguai e a Argentina. Porto Alegre: L\&PM, 2002.

HEINSFELD, Adelar. Os tratados de limites coloniais e o espaço territorial missioneiro no contexto da geopolítica hispânica para a América. In: J ORNADAS 
INTERNACIONAES SOBRE AS MISSÕESJ ESUÍTICAS, 11., 2006, Porto Alegre. Anais... Porto Alegre, 2006 (CD-ROM).

HERNÁNDEZ, J uan Luis. Las reformas del Virrey Avilés en los pueblos guaraníes de Misiones (1799-1801). Revista Prohistoria, Rosario, n. 6, p. 11-34, 2002.

HERNÁNDEZ, J uan Luis. Tumultos y motines: la conflictividad social en los pueblos guaraníes de la región misionera (1768-1799). Memoria Americana: Cuadernos de Etnohistoria, Buenos Aires, n. 8, p. 83-100, 1999.

HESPANHA, Antonio Manuel. La senda amorosa del derecho. Amor y Ivstitia en el discurso jurídico moderno. In: PETIT, Carlos (Ed.). Pasiones del jurista: amor, memoria, melancolía, imaginación. Madrid: Centro de Estudios Constitucionales, 1997. p. 23-56.

HESPANHA, Antonio. El espacio político. In: HESPANHA, Antonio. La Gracia del Derecho: economía de la cultura en la edad moderna. Madrid: Centro de Estudios Constitucionales, 1993. p. 85-121.

LANGER, Protasio Paulo. Os guarani-missioneiros e o colonialismo luso no Brasil meridional: projetos civilizatórios e faces da identidade étnica (1750-1798). Porto Alegre: Martins Livreiro, 2005.

LÁZARO AVILA, Carlos. El reformismo borbónico y los indígenas fronterizos americanos. In: GUIMERÁ, Agustín (Ed.). El reformismo borbónico. Madrid: Alianza, 1996. p. 277-292.

LÁZARO AVILA, Carlos. Las fronteras de América y los “Flandes indianos”. Madrid: CSIC, 1997.

LUCENA GIRALDO, Manuel. El reformismo de frontera. In: GUIMERÁ, Agustín (Ed.). El reformismo borbónico. Madrid: Alianza, 1996. p. 265-292.

LUCENA GIRALDO, Manuel. Imperios confusos, viajeros equivocados: españoles y portugueses en la frontera amazónica. Revista de Occidente, Madrid, v. 260, p. 24-35, 2003.

MAEDER, Ernesto. Los problemas de límites entre España y Portugal en el Río de la Plata. Resistencia: CONICET-Fundanord, 1986. Madrid: MAPFRE, 1992.

. Misiones del Paraguay: conflicto y disolución de la sociedad guaraní.

MAEDER, Ernesto; GUTIÉRREZ, Ramón. Atlas histórico del nordeste argentino. Resistencia: CONICET-FUNDANORD, 1995.

MAZZOLA, María Celeste. Félix de Azara: itinerario intelectual de un funcionario singular. TINKUY, Boletín de Investigación y Debate, Montreal, n. 2, 2008. Disponible en: <http:// www.littlm.umontreal.ca/ recherche/ publications/ TINKUY Num8_001.pdf>. Acceso en: jul. 2009. 
MÖRNER, Magnus. Algunas reflexiones sobre historia y espacio. Población y Sociedad, Tucumán, n. 3, p. 21-34, 1995.

MORO-ROMERO, Raffaele. Viajes y movilidad en los “discursos de vida” y en las autobiografías en el mundo hispánico (siglos XVI-XVIII). In: O'PHELAN GODOY, Scarlett; SALAZAR-SOLER, Carmen (Ed.). Passeurs, mediadores culturales y agentes dela primera globalización en el mundo Ibérico, siglos XVI-XIX. Lima: Pontificia Universidad Católica del Perú, 2003. p. 107-126.

PENHOS, Marta. Ver, conocer, dominar: imágenes de sudamérica a fines del siglo XVIII. Buenos Aires: Siglo XXI, 2005.

PERRONE, Alberto. Cronistas y viajeros del Nuevo Mundo. Buenos Aires: Centro Editor de América Latina, 1973.

POENITZ, Edgar; POENITZ, Alfredo. Misiones, provincia guaranítica: defensa y disolución (1768-1830). Posadas: Universitaria, 1998.

PRATT, Mary Louise. Ojos imperiales: literatura de viajes y transculturación. Buenos Aires: Universidad Nacional de Quilmes, 1987.

QUARLERI, Lia. Elite local, burocracia y reformas borbónicas: la administración de temporalidades de La Rioja. Población y sociedad, San Miguel de Tucumán, n. 8/9, p. 177-209, 2001.

QUARLERI, Lia. Rebelión y guerra en las fronteras del Plata: guaraníes, jesuitas e Imperios coloniales. Buenos Aires: Fondo de Cultura Económica, 2009.

RIPODAZ ARDAÑAZ, Daisy. Viajeros al Río de la Plata, 1700-1725. Buenos Aires: Academia Nacional de la Historia, 2002.

SAN PÍO, María Pilar de. Expediciones del siglo XVIII. Madrid: MAFRE, 1992.

SANTOS, María Cristina dos; BAPTISTA, J ean Tiago. Reduções jesuíticas e povoados de índios: controvérsias sobre a população indígena (séc. XVII-XVIII). Historia UNISINOS, São Leopoldo, v. 11, n. 2, p. 240-251, 2007.

SARREAL, J ulia. Los guaraníes y el colapso del régimen comunitario de las misiones, 1768-1800. In: XII J ORNADAS INTERNACIONALES SOBRE LAS MISIONES J ESUÍTICAS: INTERACCIONESY SENTIDOS DE LA CONVERSIÓN, 12., 2008, Buenos Aires. Anales... Buenos Aires, 2008. (CD-ROM).

WADE, Peter. Raza y etnicidad en Latinoamérica. Quito: Abya Yala, 2000.

WILDE, Guillermo. Antropología y estética del viaje. Contratiempo, Revista de Cultura y Pensamiento, n. 2, 2007. Disponible en:

$<\mathrm{http}$ :// www.revistacontratiempo.com.ar/wilde_antropologia_estetica_viaje.htm>. Acceso en: jul. 2009.

WILDE, Guillermo. Los guaraníes después de la expulsión de los jesuitas: dinámicas políticas y prácticas simbólicas. Revista Complutense de Historia de América, Madrid: Universidad Complutense de Madrid, v. 27, p. 69-109, 2001. 
WILDE, Guillermo. Orden y ambigüedad en la formación territorial de Río de la Plata a fines del siglo XVIII. Horizontes Antropológicos, Porto Alegre, n. 9, p. 105-135, 2003.

WILDE, Guillermo. Religión y poder en las misiones de guaraníes. Buenos Aires: SB, 2009.

Colaboración recibida en 12/ 03/2011y aprobado en 11/09/2011. 